\section{Aripiprazole in the treatment of primary delusional parasitosis}

The review by Lepping et $a^{1}$ points out the difficulty of engaging patients with primary delusional parasitosis in psychiatric treatment owing to their poor insight. Our clinical experience fully supports this. The authors emphasise the lack of randomised controlled studies in this field and the limited, but promising, anecdotal literature on the use of atypical antipsychotics. Their systematic review did not identify any reports of aripiprazole in the treatment of primary delusional parasitosis. However, since this review was accepted for publication, a case report has appeared reporting the successful use of aripiprazole in an 85 -year-old woman with primary delusional parasitosis. ${ }^{2}$

Aripiprazole has a unique pharmacological profile that includes partial agonist activity at dopamine $\mathrm{D}_{2}$ and serotonin $5-\mathrm{HT}_{1 \mathrm{~A}}$ receptors. It has a favourable side-effect profile relative to other antipsychotics. ${ }^{3}$ It is non-sedating and has little propensity to cause weight gain, extrapyramidal symptoms, prolactin elevation and metabolic disturbance. However, it can cause nausea and akathisia in some patients. The favourable tolerability profile may be a particular benefit in primary delusional parasitosis as these patients are often reluctant to consider antipsychotic treatment and tolerate medication poorly.

Aripiprazole has a long half-life (about $60 \mathrm{~h}$ ) compared with other oral antipsychotics, ${ }^{4}$ which means that occasional missed doses are less likely to affect clinical outcome. Consequently, aripiprazole may be particularly useful when intermitted adherence with medication is a problem, a situation often encountered in primary delusional parasitosis. Interestingly, in the five main studies of antipsychotic treatment of primary delusional parasitosis identified by Lepping et $a l,{ }^{1}$ the highest remission rate $(73 \%)$ was in the only study that assessed antipsychotic depots. ${ }^{5}$ Although the small sample sizes limit the value of cross-study comparisons, this result is consistent with the view that medication adherence is poor in primary delusional parasitosis and that treatments that can overcome this, in this case a depot antipsychotic, can lead to better outcomes.

In summary, although further evidence is needed to establish the efficacy of aripiprazole in primary delusional parasitosis, it seems reasonable to consider this drug when discussing treatment choices with patients.

\section{Declaration of interest}

P.M.H. has received fees for lecturing and consultancy from Bristol-Myers Squibb.

1 Lepping P, Russell I, Freudenmann RW. Antipsychotic treatment of primary delusional parasitosis: systematic review. Br J Psychiatry 2007; 191 198-205.

2 Rocha FL, Hara C. Aripiprazole in delusional parasitosis: case report. Prog Neuropsychopharmacol Biol Psychiatry 2007; 31: 784-6.

3 Haddad PM, Sharma SG. Adverse effects of atypical antipsychotics: differential risk and clinical implications. CNS Drugs 2007: 21: 911-36.

4 Mallikaarjun S, Salazar DE, Bramer SL. Pharmacokinetics, tolerability, and safety of aripiprazole following multiple oral dosing in normal healthy volunteers. J Clin Pharmacol 2004; 44: 179-87.

5 Frithz A. Delusions of infestation: treatment by depot injections of neuroleptics. Clin Exp Dermatol 1979; 4: 485-8.

Vinesh Narayan, Greater Manchester West Mental Health NHS Foundation Trust, Manchester M23 3BL, UK. Email: vineshnarayan@yahoo.com; Muhammad Ashfaq Peter M. Haddad, Greater Manchester West Mental Health NHS Foundation Trust,

doi: $10.1192 /$ bjp.193.3.258
Authors' reply: Narayan et al suggest that the pharmacokinetics (half-life of 60-80 h) and side-effect profile of aripiprazole may make it particularly interesting for the treatment of primary delusional parasitosis where adherence to and engagement with treatment are the most significant challenges. They mention a case report of an 85-year-old woman with primary delusional parasitosis, who fully responded to aripiprazole. ${ }^{1}$ It is interesting that our own systematic review showed that the best response rates were achieved with first-generation depot antipsychotics. ${ }^{2}$

However, other first-generation antipsychotics with relatively long half-lives did not differ from those with shorter half-lives. Experience with second-generation antipsychotics with long half-lives is limited to one case with partial remission to sertindole ${ }^{3}$ and one recent case treated with paliperidone. ${ }^{4}$ The level of efficacy of second-generation antipsychotics in delusional parasitosis is less than certain. Our own review showed that only $25 \%$ of patients treated with a second-generation antipsychotic achieved full remission in primary delusional parasitosis. The side-effect profile of aripiprazole may be advantageous with regard to the development of metabolic syndrome, but this is often less important in delusional parasitosis because of the often short period of time that patients agree to take medication. Furthermore, the common side-effect of insomnia is a real problem with aripiprazole in a patient group that already suffers from agitation and insomnia because of persistent itching.

We therefore do not agree that the current evidence available for aripiprazole makes it the substance of choice among secondgeneration antipsychotics for primary delusional parasitosis despite its favourable pharmacokinetic profile and low risk of metabolic and cardiac complications. There are substantially more successful reports on risperidone (more than 30) and olanzapine (more than 15) as well as our own positive experience with amisulpride than case reports on aripiprazole in both primary and secondary delusional parasitosis. However, clinical studies, not case reports, will be needed to further establish secondgeneration antipsychotics in delusional parasitosis and show their individual effects in this syndrome.

\section{Declaration of interest}

P.L. has received honoraria for lecturing from Lilly and BristolMyers Squibb, and was partially funded by Lilly to attend a conference in 2007.

1 Rocha FL, Hara C. Aripiprazole in delusional parasitosis: case report. Prog Neuropsychopharmacol Biol Psychiatry 2007; 31: 784-6.

2 Lepping P, Russell I, Freudenmann RW. (2007) Antipsychotic treatment of delusional parasitosis: systematic review. Br J Psychiatry 2007; 191: 198-205.

3 Yorston G. Treatment of delusional parasitosis with sertindole. Int J Geriatr Psychiatry 1997; 12: 1127-8.

4 Freudenmann RW, Kühnlein $\mathrm{P}$, Lepping $\mathrm{P}$, Schönfeldt-Lecuona C. Secondary delusional parasitosis treated with paliperidone. Clin Exp Dermatol 2008; in press.

Peter Lepping, North Wales Section of Psychological Medicine, Wrexham Academic Unit, Technology Park, Wrexham, Wales, UK. Email: peter.lepping@ new-tr.wales.nhs.uk; Roland W. Freudenmann, Department of Psychiatry, University of Ulm, Germany

doi: 10.1192/bjp.193.3.258a

\section{0 years of evolutionary theory}

'In the distant future I see open fields for more important researches. Psychology will be based on a new foundation, that of the necessary acquirement of each mental power and capacity by gradation." 